\title{
VERMILIONECTOMY AND CLINICOPATHOLOGIC PROFILE IN ACTINIC CHEILITIS - 102 CASES
}

\author{
Minicucci, EM 1; Campos, EBP 1; Almeida, JMCV ${ }^{1}$
}

! Clinical Hospital of São Paulo State University, Unesp, Medical School, Botucatu, Brazil

Introduction: Actinic Cheilitis (AC) is a malignant lesion localized principally on the lower lip vermilion, with potential to develop into Squamous Cell Carcinoma (SCC). Objective this study is to report the casuistic of AC treated by vermilionectomy, its clinic pathologic profile and association with degree of dysplasia. Methods: Between January 2006 and August 2015 were raised the total number of patients treated of AC with surgery in the oral medicine
ambulatory of Clinical Hospital of São Paulo State University (UNESP), Medical School Botucatu, Brazil. The clinic pathologic profile and
association with degree of epithelial dysplasia of AC were evaluated.

Clinical feature of AC

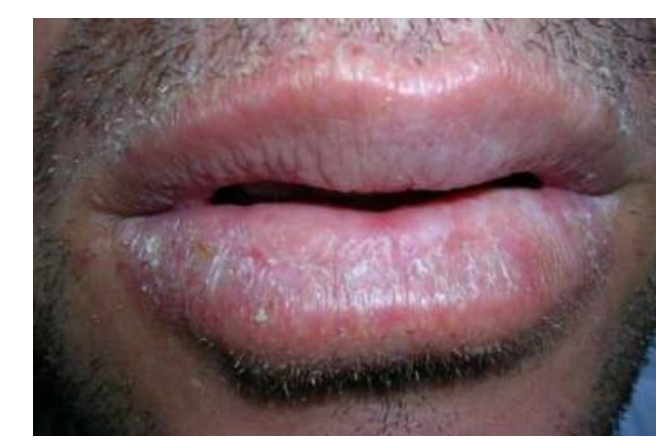

AC - scaly

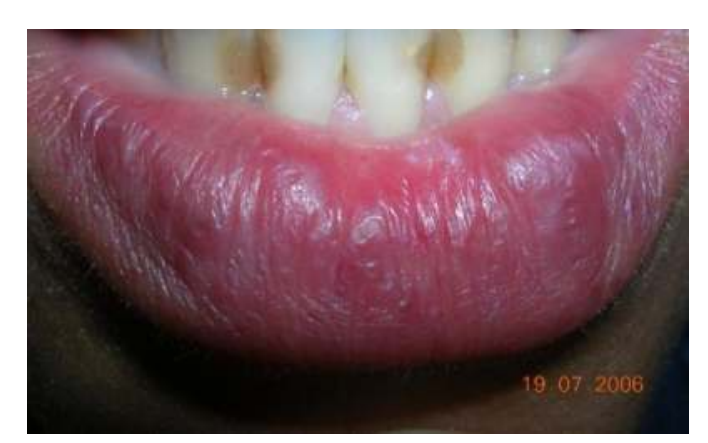

AC - swelling

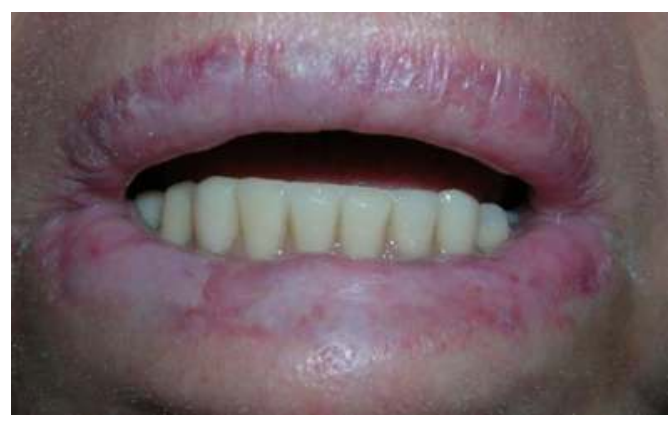

AC - leucoplakia

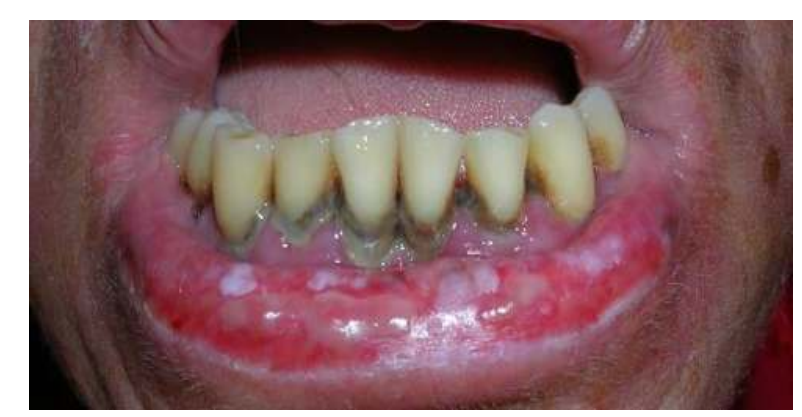

AC - ulcerated

\section{Results}
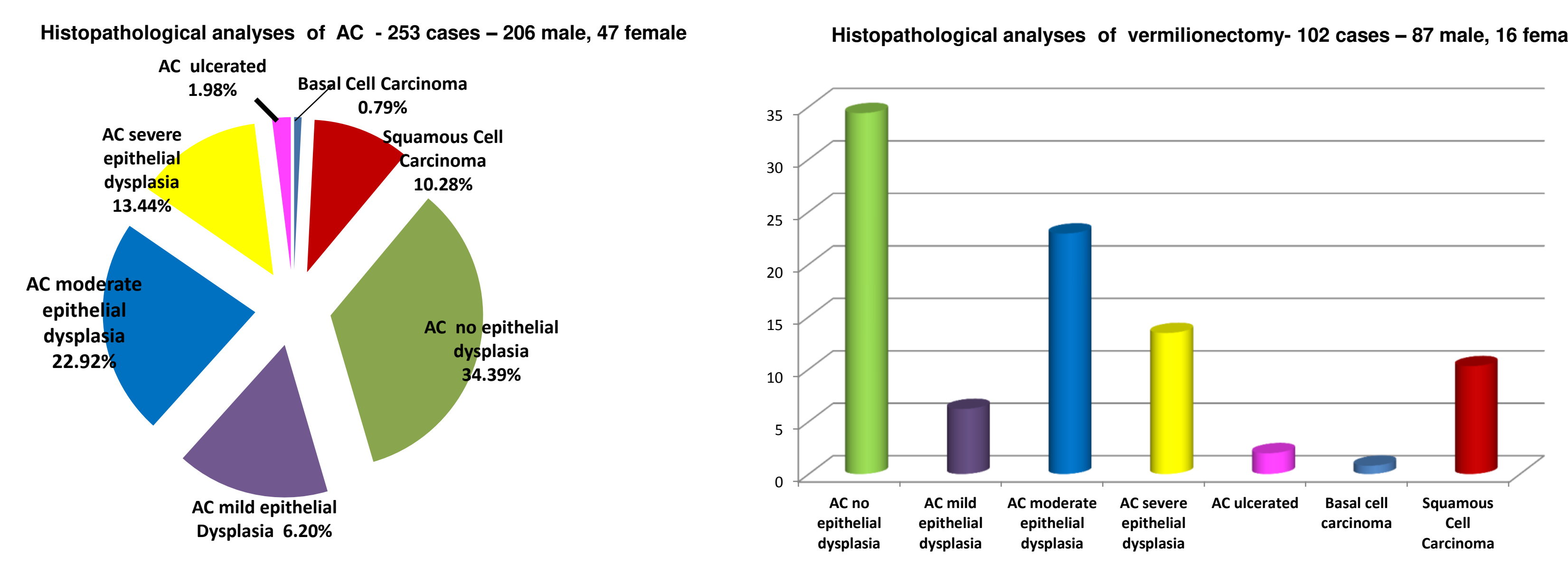

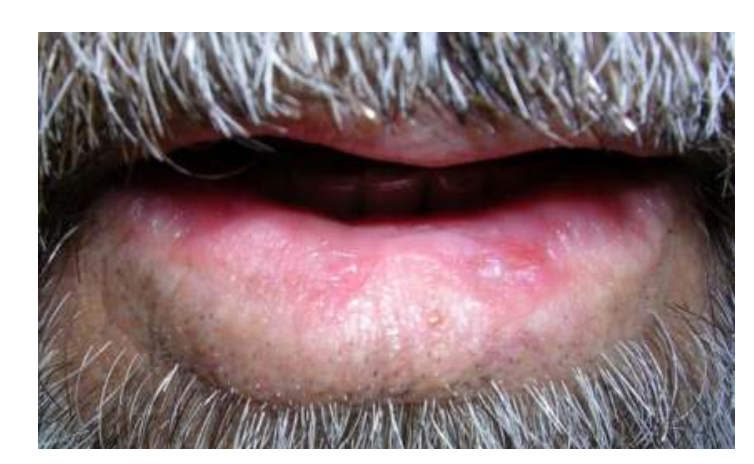

Pre operative

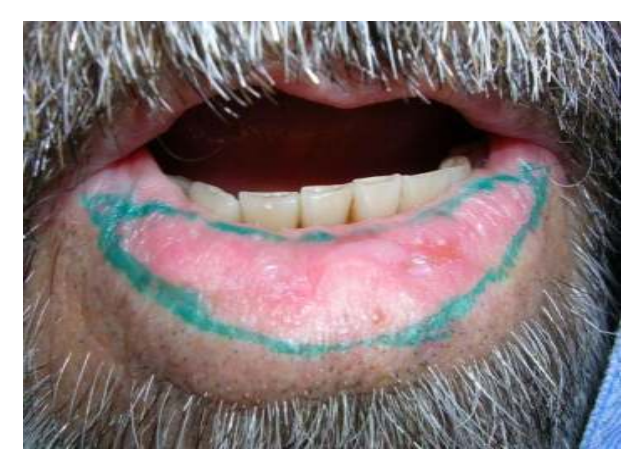

Surgical delimitation

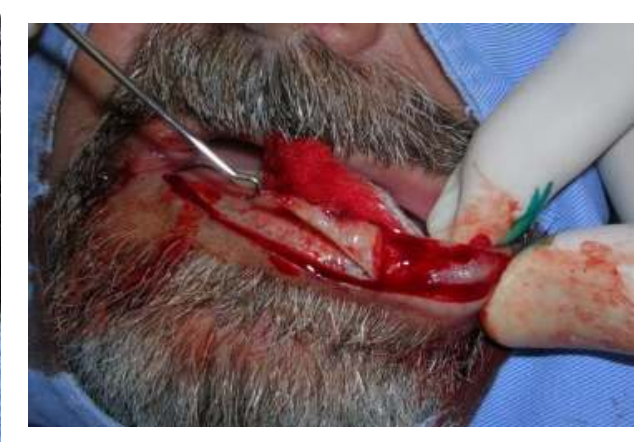

Ressection of the vermelion

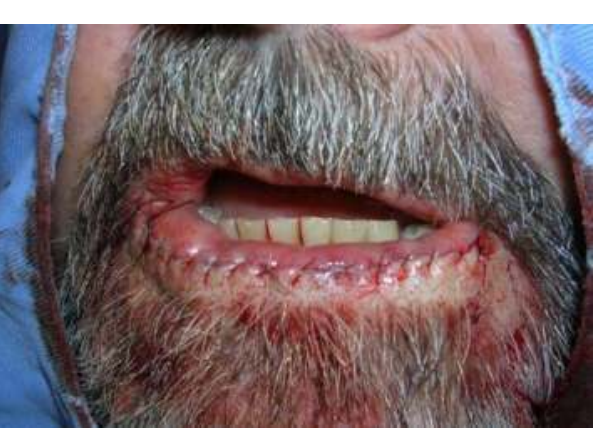

suture

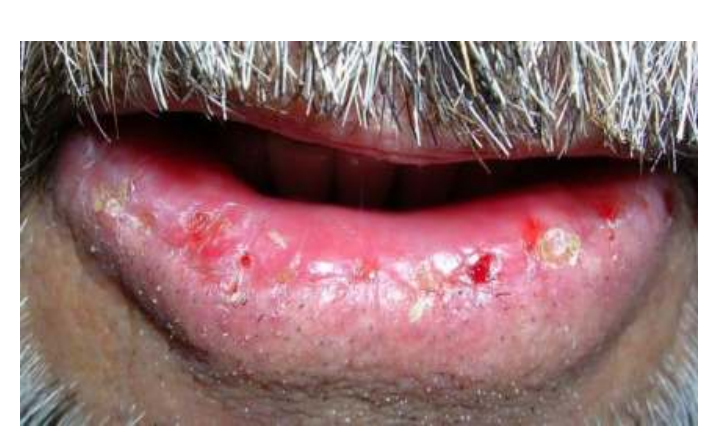

1 week after

Conclusion: Histological changes of the AC are not distributed equally by the lip vermilion, even where the clinical characteristics are homogeneous. Our study shows that most of the lesions diagnosed clinically as AC, histologically revealed SSC and AC presented moderate and severe epithelial dysplasia, and ulceration, which have a high malignant potential. The advantage of vermilionectomy is the complete removal of the epithelium altered, and histopathological review of all tissue compared with others treatments for AC, the postoperative with few symptoms and rapid healing. 